\title{
Reflections and Reminiscing on the First Catheter Ablation of the AV Junction in Man
}

\author{
Melvin Scheinman, MD* \\ University of California San Francisco, School of Medicine, University of California, San Francisco, California, USA
}

\section{Key Words \\ Catheter ablation - AV junction - DC ablation \\ Copyright $\odot 2015$ Science International Corp.}

\section{Introduction}

I am delighted to accept the invitation for me to reminisce over my experience relative to the first ablation in a human. It has been a source of great pride and fulfillment to watch the amazing growth and development of this methodology to where ablative procedures are now used to control or cure virtually all cardiac arrhythmias. I have previously described my experience in a scientific communication [1]. I am happy to elaborate in a less structured format.

In the 1970s, patients with supraventricular tachycardia (predominately atrial fibrillation) with drug refractory rapid ventricular response underwent cardiotomy with direct cryo or ligature ablation of the AV junction. I conceived of the notion of attempting to achieve the same endpoint but with use of a catheter technique.

In researching the pertinent literature I found that a Mr. Beazell had described preliminary reports of a catheter technique that used high voltage direct current (DC) shocks to the region of the AV junction localized by fluoroscopy was successful in producing AV block in canines. In addition, another fortuitous event was the acceptance of the Dr. Rolando Gonzalez to our cardiac fellowship program. In 1979, Dr.

\begin{tabular}{|c|c|}
\hline & $\begin{array}{l}\text { (C) } 2015 \text { Arrhythmia Grand Rounds } \\
\text { Published by Science International Corp. } \\
\text { ISSN } 2326-4012\end{array}$ \\
\hline $\begin{array}{l}\text { ax +1 } 2037853346 \\
\text {-Mail: agr@scienceinternational.org } \\
\text { tttp://arrhythmiagr.com/ }\end{array}$ & $\begin{array}{l}\text { Accessible online at: } \\
\text { http://arrhythmiagr.com/ }\end{array}$ \\
\hline
\end{tabular}

Gonzalez and I visited Mr. Beazell (who worked for Telectronics) at Harbor General Hospital in Los Angeles and observed his techniques.

\section{Our experimental work: 1979}

We tried the same technique, starting after our visit to Mr. Beazell's lab, but had difficulty replicating his results, no doubt due to our own faulty knowledge of the fluoroscopic landmarks in dogs. In any event, we decided to use an electrode catheter in order to record the His bundle potential so as to clearly localize the AV junction. We learned that application of shocks were more successful where a large Hus bundle potential was inscribed along with a large atrial signal.

Dr. Gonzalez performed all the animal studies including application of the DC shock and production of AV block. These studies included right heart catheterization as well as exercise studies [2]. I am very much indebted to his dedication and hard work. The animal hearts were then delivered to Drs. Lev and Bharati [3] who performed careful histologic studies and reassured us that the technique did not result in perforation of the cardiac chambers or heart valves and that the coronary circulation was not affected. We also learned early on from experiments delivering high energy shocks into a saline beaker that not all catheters could withstand the high energy (100-200 Joules) delivered. Of note during these experiments, Mr. Rubenstein, an electrical engineer working at San

\footnotetext{
* Corresponding Author:

Melvin Scheinman, MD

University of California San Francisco School of Medicine University of California

500 Parnassus Avenue, MU, San Francisco CA 94143, USA

Tel. +1 415476 5708, E-Mail: Melvin.Scheinman@ucsf.edu
} 
Francisco General Hospital, suggested use of radiofrequency (RF) energy and we did use the RF unit in the operating theatre but unfortunately abandoned this approach after we caused ventricular fibrillation in several dogs. This occurred, no doubt since we were totally ignorant in the proper usage of RF energy. It was not until several years later when Dr. Jonathan Langberg joined our program and taught about the proper electrode size and RF setting that produced safe and effective lesions in canines [4].

After several years of research to allow for proper use of the appropriate catheter and assurance of both efficacy and safety we proceeded with application to our IRB as well as to the FDA for use of this method in humans.

\section{The first patient: 1981}

We are sincerely indebted to the determination and courage of Mr. Paul Anderson, a retired oil refinery worker who volunteered to be the first patient in the world to receive this treatment. Mr. Anderson suffered from heart failure and with atrial fibrillation would develop pulmonary edema. He also had severe rheumatoid arthritis and when presented to our thoracic surgical colleague (Dr. Arthur Thomas), he was deemed too high a risk for thoracotomy and direct surgical ablation. The experimental nature of the new procedure was discussed with the patient and his wife who were very enthusiastic about participating.

I felt that due to my attachment to the new technique, it was not appropriate for me to obtain informed consent. The task was left to one of my colleagues on the cardiac EP service, Dr. David Hess who was very knowledgeable about both the patient's clinical problem as well as our experimental work. I remember Dr. Hess calling me the evening before the scheduled procedure asking that I consider doing additional animal work. I refused because we had spent a number of years with canines and I felt there was really little more to learn. In any event, when I ap- proached the patient the morning of the procedure, he was eager to get on with the ablation.

I remember a host of individuals in the laboratory that day including Drs. Morady, Hess, Ruey Sung and several cardiologists and EP fellows. We should give due credit to Mr. Booker Pullin who brilliantly fabricated all the connectors from catheter to the defibrillator.

Finally, after placement of the catheter in the proper position adjacent to the His bundle signal, the D/C shock was delivered accompanied by a flash and loud sound. The patient immediately went into complete AV block without any untoward effects. A temporary pacemaker had been placed and when AV block ensued, a permanent pacemaker was inserted.

Of interest, AV conduction resumed and a repeat procedure was required along with drug therapy. He subsequently died of congestive heart failure in 1986. He was a wonderful and courageous individual and I will never forget his admonition to "get on with this" on the morning of the procedure. The report was published in 1982 [5]. This was followed by successful ablation of a posteroseptal accessory pathway in 1984 and published the following year [6].

It has been nothing short of incredible for me to watch the remarkable evolution of the catheter ablation technique to all manners of complex arrhythmias. The most remarkable part of this as a clinician is to tell a patient that they are actually cured of their arrhythmia problem and can lead a normal life.

\section{Conflict of Interest}

The authors have no conflict of interest relevant to this publication.

Comment on this Article or Ask a Question 


\section{References}

1. Scheinman M. Reflections on the first catheter ablation of the atrioventricular junction. Pacing Clin Electrophysiol. 2003;26(12):2315-2316. DOI: 10.1111/j.1540-8159.2003.00366.x

2. Scheinman MM, Gonzalez RP. Fascicular block and acute myocardial infarction. JAMA. 1980;244(23):2646-2649. DOI: 10.1001/jama.1980.03310230046027

3. Bharati S, Scheinman M, Lev M. Histologic findings of the heart and the conduction system in the first patient who underwent catheter ablation. PACE. 1992;(9):1291-1299. DOI: 10.1001/ jama.1980.03310230046027
4. Franklin JO, Langberg JJ, Oeff $M$, Finkbeiner WE, Herre JM, Griffin JC, et al. Catheter ablation of canine myocardium with radiofrequency energy. PACE. 1989;(1 Pt 2):170-176. PMID: 2466250

5. Scheinman MM, Morady F, Hess DS, Gonzales R. Catheter-induced ablation of the atrioventricular junction to control refractory supraventricular arrhythmias. JAMA. 1982;248(7):851-855. DOI: 10.1001/ jama.1982.03330070039027

6. Morady F, Scheinman MM, Winston S, DiCarlo L, Davis J, Griffin J, et. al. Efficacy and safety of transcatheter ablation of posteroseptal accessory pathways. Circulation 1985;72:170. DOI: 10.1161/01.CIR.72.1.170
Cite this article as: Scheinman M. Reflections and reminiscing on the first catheter ablation of the AV junction in man. Arrhythmia Grand Rounds 2015;1(1): 44-46. DOI: http://dx.doi. org/10.12945/j.agr.2015.00022-14 